\title{
Stromal Osseous Metaplasia in Ovarian Serous Cystadenocarcinoma
}

\author{
Doaa A. Alghamdi, MD, SB Path, Layla S. Abdullah, FRCPC, MIAC, \\ Ahmed A. Mousa ${ }^{1}$, FRCSC, FACOG, and Sumiah A. Shinawi, MD \\ Department of Pathology and 'Obstetrics and Gynecology \\ Faculty of Medicine, King Abdulaziz University \\ Jeddah, Saudi Arabia
}

\section{Correspondence}

Dr. Doaa A. Alghamdi

P.O. Box 80215, Jeddah 21589, Saudi Arabia

e.M: dalghamdi@kau.edu.sa

Submission: 21 May 2015

Accepted: $\quad 10$ Aug. 2015

\section{Citation}

Alghamdi DA, Abdullah LS, Mousa AA, Shinawi

SA. Stromal osseous metaplasia in ovarian

serous cystadenocarcinoma. JKAU Med Sci

2016; 23 (1): 41-46. DOI: 10.4197/Med. 23.1.6

\begin{abstract}
Ovarian ossification is a rare pathological condition that may be encountered in neoplastic as well as in non-neoplastic contexts. Its etiology and pathogenesis are controversial. We report the case of a 33-year old female $(P 6+1)$ who presented with a 4 month history of abdominal distention and amenorrhea. Radiological investigations showed complex pelvi abdominal mass with foci of calcification. The patient underwent total hysterectomy with bilateral salpingo-oophorectomy. Gross pathology findings showed bilateral enlargement of the ovaries and gritty sensation of ovary in slicing. Microscopic pathology showed mature lamellate bone in the wall of right ovary invaded by serous neoplastic cells.
\end{abstract}

\section{Keywords}

Serous cystadenocarcinoma; Cystcarcinoma; Ovary, Ovarian; Osseous metaplasia; Tumor; Psammoma bodies; Calcification

\section{Introduction}

0 varian serous cyst carcinoma is a common ovarian surface tumor ${ }^{[1,2] " I S S N " ~: ~ " 1542-4863 ", ~}$ "PMID" : "21296855", "abstract" : "The global burden of cancer continues to increase largely because of the aging and growth of the world population alongside an increasing adoption of cancer-causing behaviors, particularly smoking, in economically developing countries. Based on the GLOBOCAN 2008 estimates, about 12.7 million cancer cases and 7.6 million cancer deaths are estimated to have occurred in 2008; of these, $56 \%$ of the cases and $64 \%$ of the deaths occurred in the economically developing world. Breast cancer is the most frequently diagnosed cancer and the leading cause of cancer death among females, accounting for $23 \%$ of the total cancer cases and $14 \%$ of the cancer deaths. Lung cancer is the leading cancer site in males, comprising $17 \%$ of the total new cancer cases and $23 \%$ of the total cancer deaths. Breast cancer is now also the leading cause of cancer death among females in economically developing countries, a shift from the previous decade during which the most common cause of cancer death was cervical cancer. Further, the mortality burden for lung cancer among females in developing countries is as high as the burden for cervical cancer, with each accounting for $11 \%$ of the total female cancer deaths. Although overall cancer incidence rates in the developing world are half those seen in the developed world in both sexes, the overall cancer mortality rates are generally similar. Cancer survival tends to be poorer in developing countries, most likely because of a combination of a late stage at diagnosis and limited access to timely and standard treatment. A substantial proportion of the worldwide burden of cancer could be prevented through the 
application of existing cancer control knowledge and by implementing programs for tobacco control, vaccination (for liver and cervical cancers. However, the presence of mature bone in stroma of (ovarian) serous carcinoma is an uncommon finding. Only three cases of (ovarian) serous cystcarcinoma with osseous metaplasia have been reported in the literature so far $^{[3,4]}$. We are reporting a fourth case of (ovarian) serous cystocarcinoma with mature bone.

\section{Case Report}

This is the case of a 33-year old woman (P6 + 1) with last delivery 3 years ago, who was admitted with a chief complaint of recurrent abdominal pain and severe abdominal distention during the past 4 months. She also complained of amenorrhea for the past 3 months; however, no gastrointestinal symptoms were noted. Medical history taking showed no history of per vaginal bleeding, hematochezia or hematuria.

On examination, the patient presented in an altered general state, painful but alert, conscious, and oriented. Abdominal examination revealed a large ascites and in rectal palpation a huge posteriorly fixed mass was palpated. Per vaginal examination showed an anteriorly dilated cervix. No palpable lymph nodes were found in the groin region.

Laboratory Investigations revealed a Ca-125 = $1806 \mathrm{IU} / \mathrm{mL}$ (Reference range: $0-35 \mathrm{IU} / \mathrm{mL}$ ); $\mathrm{BHCG}=$ $4.46 \mathrm{IU} / \mathrm{mL} ; C E A=0.22 \mathrm{ng} / \mathrm{mL}$ (Reference range: 0 - 3.4) and CA-19.9 = $12.11 \mathrm{IU} / \mathrm{mL}$ (Reference range: $0-39 \mathrm{lU} /$ $\mathrm{mL})$.

Abdominopelvic computerized tomography (CT) scan (Fig. 1) was performed and showed a large pelvi abdominal mass measuring $15 \times 14 \times 10 \mathrm{~cm}$, encasing the sigmoid colon. The mass was complex, showing solid and cystic components as well as calcifications and was visible to the naked eye. Multiple mesenteric deposits were also visible; the largest measured $6.8 \times 4 \mathrm{~cm}$. Large ascites and bilateral moderate hydronephrosis with hydroureter were also mentioned.

The patient underwent total hysterectomy with bilateral salpingo-oophorectomy. Gross pathology examination of the specimen showed a bilateral enlargement of the ovaries: the right one measuring

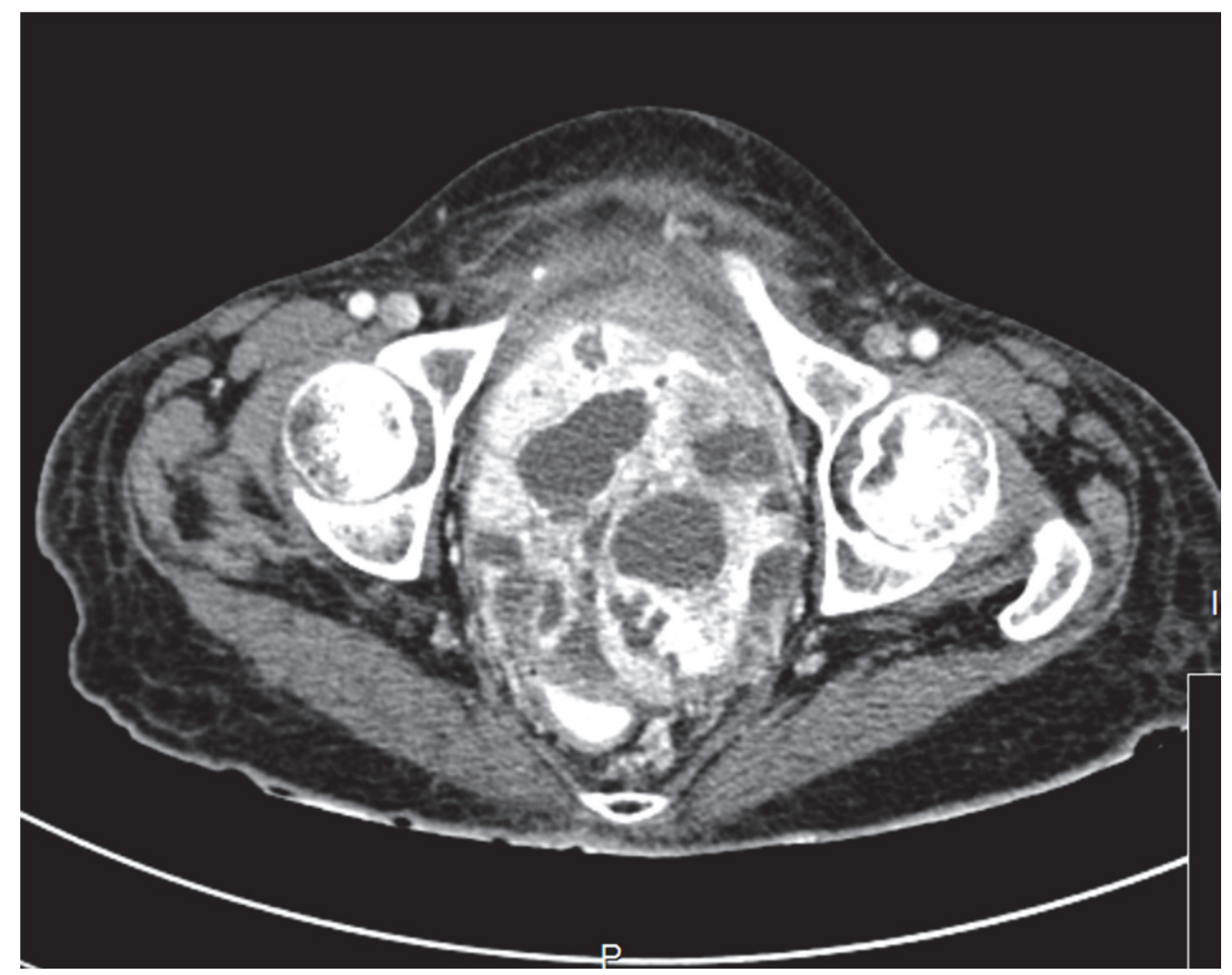

Figure 1. CT scan for abdomen and pelvis shows complex pelvi abdominal mass containing solid and cystic components as well as calcifications. 
$10 \times 10 \times 3 \mathrm{~cm}$ and the left one measuring $4.2 \times 3.2 \times$ $3 \mathrm{~cm}$. The right ovary was ruptured and adherent to the rectum and uterus. Cut sections of both ovaries showed soft, friable, gray-tan and hemorrhagic tissue with areas of gritty sensation in the right ovary.
Microscopic examination (Figs. 2 and 3) revealed a neoplastic growth of both ovaries arranged in solid sheets and papillae, surrounded by desmoplastic stroma. This growth was composed of atypical serous cells with pleomorphic nuclei, some of which were

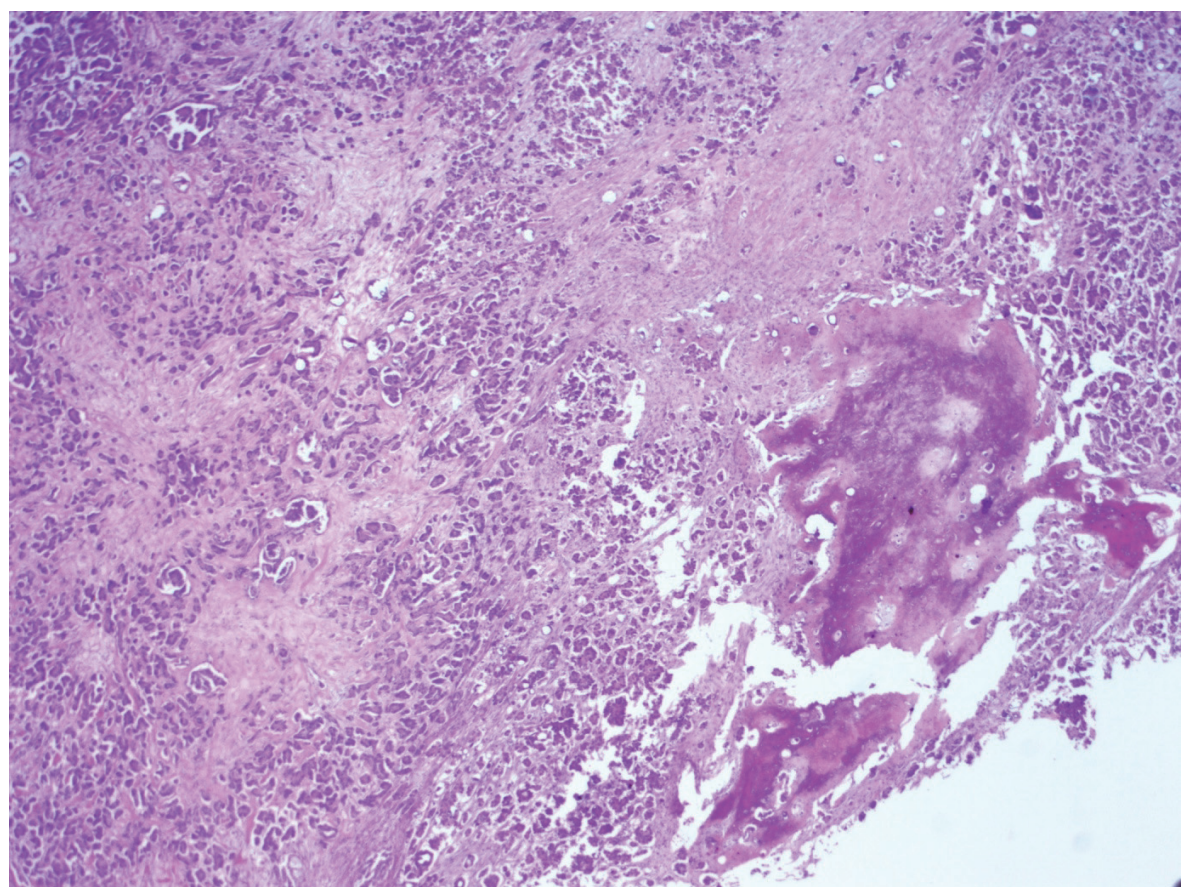

Figure 2. Low-power view of right ovary (4x). Showing serous epithelium neoplasm and osseous metaplasia.

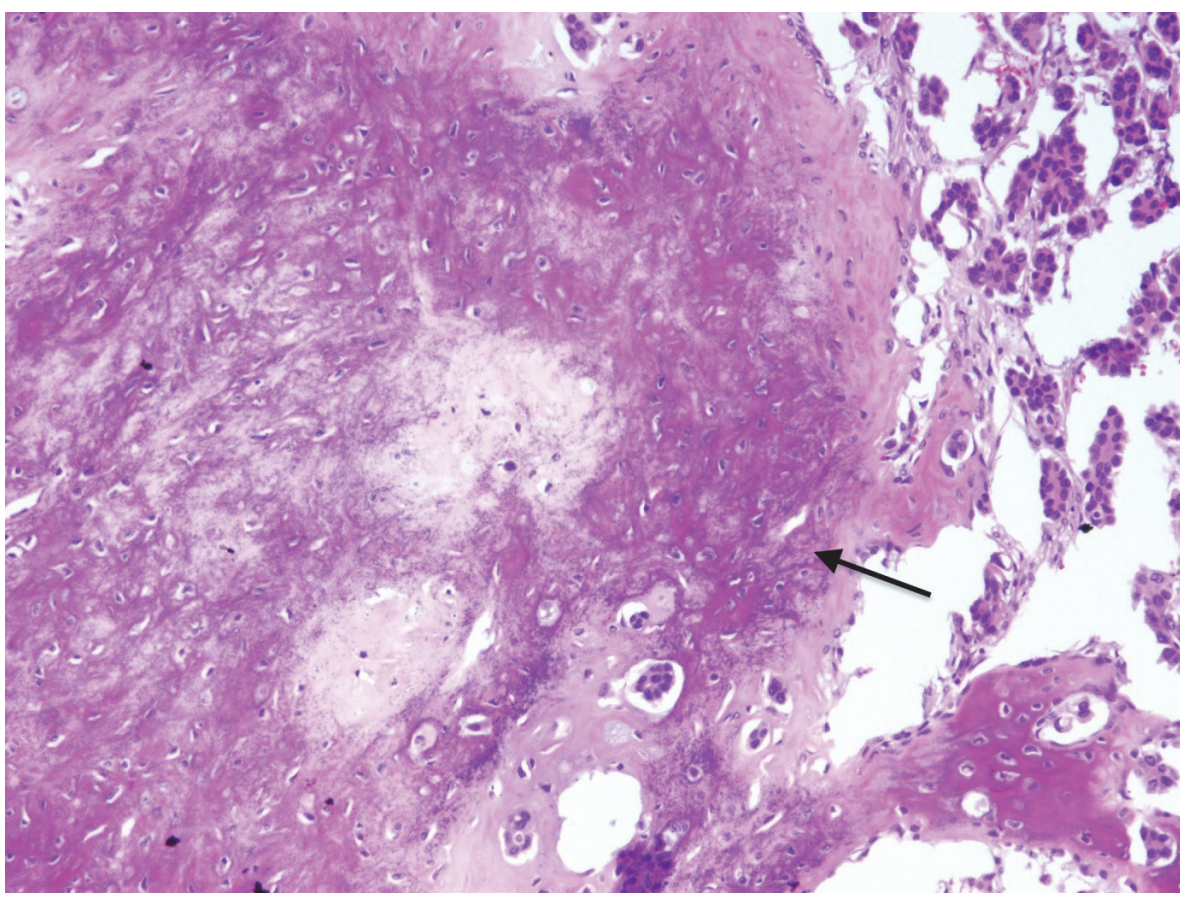

Figure 3. High-power view of right ovary (20x). The lamellar bone (arrows) is invaded by epithelial cluster of serous adenocarcinoma. 
multinucleated and hyperchromatic and some were vesicular with prominent nucleoli. Occasional mitosis was seen. Numerous psammoma bodies (concentric lamellated calcified structures) were found, as well as a focus of mature lamellate bone in surrounding stroma in the right ovary.

The pathology report concluded a serous cystocarcinoma of the ovary with mature osseous metaplasia.

\section{Discussion}

The presence of mature lamellate bone in an ovary is usually seen in association with ovarian teratoma ${ }^{[5]}$.

Isolated bony trabecula in non teratomatous ovarian neoplasm is a very rare phenomena ${ }^{[6]}$.

The non teratomatous ovarian tumors reported with mature bony trabecula include the following: Two cases of Mucinous cysteadenoma ${ }^{[7,8]}$, one benign serous cystadenoma ${ }^{[9]}$, three cases of sex cord stromal tumor ${ }^{[10-12]}$, one case of endometrioid adenocarcinoma ${ }^{[13]}$ and three cases of serous cystadenocarcinoma $a^{[3,4]}$. So up to my knowledge our case is the fourth serous cystadenocarcinoma with mature bony trabecula in the wall.

On the other hand ovarian ossification also reported in non-neoplastic ovarian condition like endometriosis $\mathrm{s}^{[5,6,14-16]}$ and simple follicular cyst with urogenital abnormality ${ }^{[17]}$.

Many hypotheses have been proposed in literature to explain the origin and pathogenesis of ovarian stroma ossification, one of which suggests in benign (non-neoplastic) lesions the concurrence of infarction and chronic inflammation consequent to torsion ${ }^{[5,16,18]}$ and leading to hyalinization dystrophic calcification. In neoplastic lesions, ossifications are attributed to a form of bony metaplasia of ovarian stroma induced by bone growth factors that are secreted by neoplastic cells $s^{[11,13]}$.

The pathogenesis of psammoma bodies that is a characteristic feature of serous neoplasm, on the other hand, is still not clear and some authors suggest spontaneous induction or formation secondary to tissue necrosis ${ }^{[6]}$.

The prognostic value of ossification in ovarian neoplasms, especially in serous tumors, is still unknown $^{[13]}$.

Ossification has also been reported in other female reproductive system organs including cervix, endometrium, and vagina ${ }^{[19-21]}$; however, a previous history of pelvic trauma or irritation consequent to surgery or radiotherapy is reported in the majority of these cases.

\section{Conclusion}

Ovarian ossification can be identified in a variety of benign and malignant ovarian neoplasm. The case we report is the fourth case of serous cystadenocarcinoma with ossification and bony metaplasia.

\section{Conflict of Interest}

The authors have no conflict of interest.

\section{Disclosure}

None of the authors received any type of commercial support either in forms of compensation or financial for this study. They have no financial interest in any of the products or devices, or drugs mentioned in this article.

\section{Ethical Approval}

Obtained.

\section{Rerefences}

[1] Jemal A, Bray F, Center MM, Ferlay J, Ward E, Forman D. Global cancer statistics. CA Cancer J Clin 2011; 61(2): 6990.

[2] Li J, Fadare O, Xiang L, Kong B, Zheng W. Ovarian serous carcinoma: recent concepts on its origin and carcinogenesis. J Hematol Oncol 2012; 5: 8.

[3] Bosscher J, Barnhill D, O'Connor D, Doering D, Nash J, Park R. Osseous metaplasia in ovarian papillary serous cystadenocarcinoma. Gynecol Oncol 1990; 39(2): 228-231.

[4] Barua R, Cox LW. Occurrence of bone in serous cystadenocarcinoma of the ovary. Aust New Zeal J Obstet Gynaecol 1982; 22(3): 183-186.

[5] Singh AK, Singh MK, Ghavghve S, Agarwal A, Goel MM. Ossification of ovarian cyst: a rare case report. J Evol Med Dent Sci 2013; 2(25): 4523-4527.

[6] Lanzafame S, Nicolosi AG, Caltabiano R. Bilateral massive osseous metaplasia in ovaries:"ovarian stones". Gynecol Surg 2007; 4(3): 191-193.

[7] Zahn CM, Kendall BS. Heterotopic bone in the ovary associated with a mucinous cystadenoma. Mil Med 2001; 166(10): 915-917.

[8] Misselevich I, Boss JH. Metaplastic bone in a mucinous cystadenoma of the ovary. Pathol Res Pract 2000; 196(12): 847-848. 
[9] Miliaras D, Ketikidou M, Pervana S. Osseous metaplasia in ovarian tumors: A case with serous cystadenoma. J Clin Pathol 2007; 60(5): 582-583.

[10] Morizane M, Ohara N, Mori T, Murao S. Ossifying luteinized thecoma of the ovary. Arch Gynecol Obstet 2003; 267(3): 167-169.

[11] Pervatikar SK, Rao R, Dinesh US. Ossifying luteinized thecoma of the ovary with endometrial adenocarcinoma. Indian J Pathol Microbiol 2009; 52(2): 222-224.

[12] Mooney EE, Vaidya KP, Tavassoli FA. Ossifying welldifferentiated Sertoli-Leydig cell tumor of the ovary. Ann Diagn Pathol 2000; 4(1): 34-38.

[13] Mukonoweshuro P, Oriowolo A. Stromal osseous metaplasia in a low-grade ovarian adenocarcinoma. Gynecol Oncol 2005; 99(1): 222-224.

[14] Bedaiwy MA, Goldberg JM, Biscotti CV. Recurrent osseous metaplasia of the cervix after loop electrosurgical excision. Obstet Gynecol 2001; 98(5 Pt 2): 968-970.

[15] Shaco-Levy R, Lazer T, Piura B, Wiznitzer A. Ovarian ossification associated with endometriosis. Clin Exp Obstet Gynecol 2007; 34(2): 113-114.

[16] Su WH, Wang PH, Chang SP. Ovarian stone. A case report. J Reprod Med 2002; 47(4): 329-331.

[17] Godbole P, Outram A, Sebire N. Osseous metaplasia in a benign ovarian cyst in association with cloacal anomaly. J Clin Pathol 2005; 58(3): 334-335.

[18] Kennedy LA, Pinckney LE, Currarino G, Votteler TP. Amputated calcified ovaries in children. Radiology 1981; 141(1): 83-86.

[19] Badawy SZA, Kasello DJ, Powers C, Elia G, Wojtowycz AR. Supernumerary ovary with an endometrioma and osseous metaplasia: A case report. Am J Obstet Gynecol 1995; 173(5): 1623-1624.

[20] Umashankar T, Patted S, Handigund RS. Endometrial osseous metaplasia: Clinicopathological study of a case and literature review. J Hum Reprod Sci 2010; 3(2): 102104.

[21] Landim FM, Tavares JM, Melo Braga DN, da Silva JE Jr, Bastos Filho JB, Feitosa RG. Vaginal osseous metaplasia. Arch Gynecol Obstet 2009; 279(3): 381-384. 


\section{حالة تحوّل عظمي في سرطان المبيض المصلي}

\section{دعاء علي الغامدي، وليلى صالح عبدالله، واحمد انس موسىى'، وسميه احمد شناوي

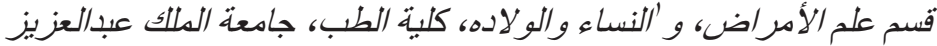

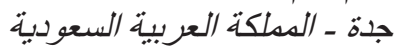

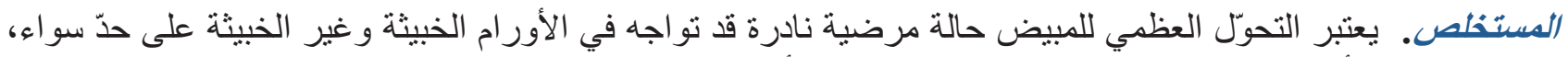

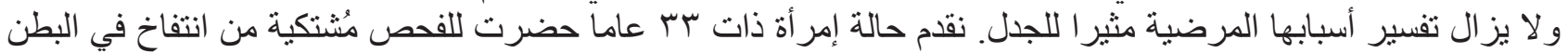

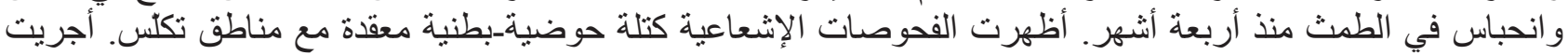

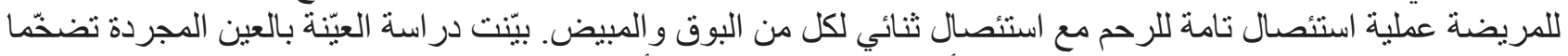

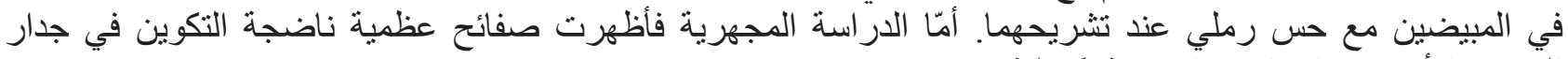
المبيض الأيمن تجناحها خلاياً ورمية مَصلية. 